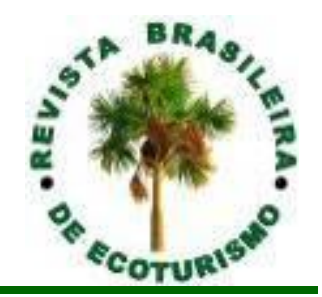

\title{
Potencialidades turísticas e aspectos socioambientais em duas comunidades autoidentificadas indígenas no Rio Grande do Norte
}

\section{Tourism potential and socio-environmental aspects in two self- identified indigenous communities in Rio Grande do Norte (Brazil)}

\author{
Jacqueline Cunha de Vasconcelos Martins, Tayse Michelle Campos da Silva, \\ Alan Martins de Oliveira, Edson Vicente da Silva, \\ Ingride Pamilly Ribeiro Araujo de Oliveira
}

\begin{abstract}
RESUMO: O processo de invasão e colonização do Brasil ocasionou aos povos nativos perda de numerosa população, de grande parte da diversidade cultural e de extensos territórios. Especialmente no Nordeste, onde iniciou esse processo, tais fatores contribuíram para as mudanças socioculturais das populações indígenas, hoje chamadas de "miscigenadas". Todavia, com a autoidentificação no Censo de 2010, é crescente o número de comunidades que tem integrado o movimento indígena por reconhecimento e direitos. O desenvolvimento de projetos de etnoturismo pode contribuir para o fortalecimento e maior visibilidade desses agrupamentos sociais, além ser uma fonte sustentável de geração de renda. No entanto, a literatura aponta limitações desse tipo de intervenção. Assim, o objetivo deste artigo é evidenciar as potencialidades turísticas em territórios de duas comunidades autoidentificadas indígenas no Rio Grande do Norte. É uma pesquisa com enfoque qualitativo que constou de três etapas: visitas às comunidades; observações in loco e registro fotográfico; entrevistas semiestruturadas com lideranças locais. Na Comunidade Mendonça do Amarelão em João Câmara-RN, com cerca de 1.100 pessoas, as atrações etnoturísticas incluem trilha ecológica em lugares como a "pedra das letras" com pinturas rupestres e o ensino do tupi na escola local; além de rituais como a dança do Toré. A Comunidade Caboclos do Assu, no município de Assu-RN, por sua vez, tem em torno de 100 pessoas e as possibilidades em destaque são 0 açude do riacho, a vegetação nativa e, principalmente, a riqueza nas vidas das pessoas do lugar. Em relação ao potencial para receber grupos, na primeira citada há maior capacidade de infraestrutura e, embora tenham experiência com grupos numerosos, não têm com turistas. Assim, especialmente em Caboclos do Assu requer maior aprofundamento de estudo na perspectiva do turismo sustentável, sendo necessário empenho do poder público e parcerias com organizações não governamentais.
\end{abstract}

PALAVRAS CHAVE: Turismo de Base Comunitária; Valorização Local; Geração de Renda; Sustentabilidade. 
ABSTRACT: The process of invasion and colonization of Brazil caused the native peoples to lose a large population, much of the cultural diversity and extensive territories. Especially in the Northeast, where this process was initiated, such factors contributed to the sociocultural changes of the indigenous populations, today called "mixed-race". Nevertheless, with the self-identification in the 2010 Census, there is a growing number of communities that have integrated the indigenous movement by recognition and rights. The development of ethnotourism projects can contribute to the strengthening and greater visibility of these social groupings, in addition to being a sustainable source of income generation. However, the literature points out limitations of this type of intervention. Therefore, the objective of this article is to highlight the tourist potential in territories of two self-identified indigenous communities in Rio Grande do Norte. It is a research with qualitative focus that consisted of three stages: visits to the communities; in loco observations and photographic records; semistructured interviews with local leaders. In the Mendonça do Amarelão Community in João Câmara-RN, with about 1,100 people, ethnotourism attractions include ecological trail in places like "Pedra das Letras" (stone of the letters) with cave paintings and the teaching of the Tupi language in the local school; as well as rituals such as the Toré dance. The community Caboclos do Assu, in Assu-RN, has about 100 people and the possibilities are the weir, native vegetation and, above all, the richness of the lives of local people. Regarding the potential to receive groups, in the first mentioned there is greater capacity of infrastructure and, although they have experience with numerous groups, they do not have experience with tourists. Thus, especially in Caboclos do Assu, a deeper study of the perspective of sustainable tourism is required, being necessary commitment of the public law and partnerships with non-governmental organizations.

KEYWORDS: Community-Based Tourism; Local Valorization; Income Generation; Sustainability.

\section{Introdução}

Os povos autóctones do território brasileiro perderam numerosa população, grande parte da diversidade cultural e extensos territórios e, na atualidade, continuam a ser oprimidos em seus direitos políticos, sociais e culturais (GOMES, 2010). Os nativos dessa terra pertenciam a diversos povos com culturas, tradições, línguas e crenças diferentes, mas todos passaram a ser denominados "índios" pelos agentes externos, os invasores colonizadores. Durante o processo de colonização no Brasil, que iniciou pela região Nordeste, vários fatores como morticínios, imposição social, cultural, econômica e territorial do Estado sobre as populações etnicamente diferenciadas entre outros, contribuíram para as mudanças socioculturais nas populações indígenas do Nordeste. Segundo Oliveira (1998, p.51): "É a partir de fatos de natureza política - demandas quanto à terra e assistência formuladas ao órgão indigenista - que os atuais povos indígenas do Nordeste são colocados como objeto de atenção para os antropólogos sediados nas universidades da região".

Os povos indígenas da região Nordeste do Brasil são chamados de miscigenados, remanescentes, descendentes de índios ou aculturados, o que carrega o peso da insegurança da sociedade, do poder público e até de pesquisadores em falar sobre estes com a força da autoafirmação. $O$ que identifica um povo indígena é a memória e o sentimento de pertença ao seu povo, à sua terra e à sua história, visto que não é possível reconhecer qualquer forma de organização indígena quando nem mesmo se reconhece a existência desses povos. 
Todavia, com a possibilidade de autoidenficiação no último Censo do IBGE (2010) e contrariando a historiografia clássica, como critica Macedo (2011) sobre o "desaparecimento" desses povos no Estado do Rio Grande do Norte, comunidades passaram a integrar o movimento indígena na luta por reconhecimento e direitos.

Em 2005, marco da mobilização no estado, três comunidades se autoidentificaram indígenas, em audiência pública na Assembleia Legislativa estadual, Mendonça do Amarelão, Caboclos do Assu e Eleotérios do Catu, (VIEIRA e KÓS, 2017). Posteriormente, outras também realizaram o autorreconhecimento (GUERRA, 2017) e tem sido crescente a inserção de comunidades autoafirmadas indígenas no Estado. Em 2015, atendendo à recomendação do Ministério Público Federal e da Advocacia Geral da União, a Fundação Nacional do Índio - FUNAI instituiu um Grupo de Trabalho - GT para identificar e delimitar a TI de uma das comunidades em decorrência de conflitos fundiários (VIEIRA; KÓS, 2017; BRASIL, 2019).

O Conselho Indigenista Missionário - CIMI (2016) também salienta que a demarcação de Terras Indígenas - Tls no RN é reivindicada desde 2005 e a Associação Nacional dos Povos Indigenistas - ANAí (2016), que faz o acompanhamento da situação fundiária, igualmente destaca a existência destes em terras potiguares. Além disso, pesquisas têm sido desenvolvidas em programas de pós-graduação de universidades públicas regionais sobre a presença indígena no Estado e Região, a exemplo de estudos sobre os "Mendonça do Amarelão" (GUERRA, 2007) em João Câmara-RN e sobre os "Caboclos do Assu" localizados no município de Assu-RN (OLIVEIRA, 2014).

Conforme o Conselho Indigenista Missionário (CIMI, 2016), nos mapas oficiais estão representados $36,7 \%$ dos territórios indígenas do Brasil, uma vez que consideram apenas as terras indígenas demarcadas ou em processo de demarcação, a exemplo dos disponíveis pela FUNAI (2018). Todavia, no Rio Grande do Norte tem quatro comunidades indígenas com Qualificação de Reinvindicação de Demarcação de Terras feita e registrada no Departamento de Proteção Territorial da FUNAI - Caboclos do Assu (Assu), Amarelão (João Câmara), Tapará (Macaíba) e Catu (Canguaretama). Vale esclarecer que essa etapa, antecede as fases do procedimento demarcatório, ou seja, antecede a formação do GT (FUNAI, 2019).

Segundo o Instituto Brasileiro de Geografia e Estatística (IBGE, 2012), a população indígena no RN passou de 394 em 1991 para 3.168 em 2000. Este número decresceu em 2010 para 2.597. Como ilustração de que o censo oficial subestima a população do Estado, a Associação Comunitária do Amarelão - ACA (2018) realizou censo local, onde 966 pessoas no Amarelão se autodeclararam indígenas, porém nos dados do IBGE, há registro de apenas 324 pessoas e menos ainda nas demais localidades.

Esse foi um dos motivos que levou o Movimento Indígena do RN a convidar um representante do IBGE para prestar esclarecimentos durante a II Assembleia dos Povos Indígenas do RN - II AIRN, realizada em novembro de 2011 no município de Goianinha-RN. Na ocasião, lideranças indígenas afirmaram que o número reduzido das populações no referido censo foi reflexo de falha metodológica dos recenseadores na aplicação do questionário, uma vez que frequentemente omitiram a pergunta sobre raça-cor, impactando em dados estatísticos que não refletem a realidade. Vale reforçar que tal fato não se configurou em negação de identidade pelos próprios indígenas. Como encaminhamento, foi proposto ao citado representante a capacitação adequada aos recenseadores quanto à autodeclaração étnica. 
A luta por reconhecimento e direitos aliada à insuficiência de políticas públicas interfere fortemente na sustentabilidade e preservação sociocultural, ambiental e econômica das referidas comunidades. Desse modo, considerando que a sustentabilidade deve partir do local, respeitando os ecossistemas com suas diversas formas de vida, viabilizando o desenvolvimento e priorizando o ser humano em detrimento do capital (BOFF, 2012), o objetivo deste artigo é apresentar possibilidades alternativas viáveis de geração de renda, incluindo potencialidades turísticas em duas comunidades autoafirmadas indígenas, destacando aspectos socioambientais e culturais.

\section{Valorização local e geração de renda}

No ambiente rural brasileiro, os modelos convencionais de produção não se aplicam de forma sustentável em comunidades tradicionais ou familiares e notadamente em comunidades indígenas. Isso é particularmente importante nas regiões com escassez de água, como o semiárido brasileiro, com efeito direto na capacidade de produção agrícola e pecuária, o que implica na necessidade de buscar outras fontes de renda.

Daí a necessidade de desenvolvimento e adaptação de novas tecnologias e ideias associadas à valorização local, onde as atividades não agrícolas podem ser de grande impacto positivo na geração de renda (SOUZA et al., 2011). Diante da existência autoafirmada de povos indígenas no Rio Grande do Norte, o etnoturismo desponta como uma possível fonte de renda, além do desenvolvimento de outras atividades econômicas não associadas à produção agrícola e pecuária.

A literatura internacional, segundo Pereiro (2013), aponta três perspectivas na realidade da América Latina, em relação ao turismo em comunidades indígenas: o otimista, o pessimista e o adaptativo. Na perspectiva apontada como otimista, é quando a comunidade se empodera da atividade de tal forma que efetivamente se beneficia, inclusive financeiramente, e o gerenciamento não sofre intervenção predatória de terceiros. A segunda perspectiva é a do descontentamento, devido aos impactos negativos do turismo nessas comunidades que coloca em dúvida os reais benefícios, uma vez que as vantagens ficam para as empresas intermediárias de turismo. Na terceira perspectiva, adaptativa, de forma crítica são avaliados os efeitos positivos e negativos de acordo com o contexto local. Nesta a gestão indígena do etnoturismo, mantém o controle sobre seus bens naturais e culturais e, inclusive, autonomia para "dizer não".

É necessário atentar aos impactos da "espetacularização" da cultura indígena, que de origem nativa não pode ser tratada como "exótica", quer seja por agentes públicos ou privados. Logo, as visitações nessas comunidades devem ser feitas de forma respeitosa por pesquisadores, sociedade civil, indústria cultural, empresas de turismo e de publicidade (CARVALHO, 2010).

No Brasil, o Decreto no 7.747/2012 que Institui a Política Nacional de Gestão Territorial e Ambiental de Terras Indígenas - PNGATI determina no eixo sobre o uso sustentável de recursos naturais e iniciativas produtivas indígenas, um item específico sobre o etnoturismo e ecoturismo, que enfatiza o respeito à decisão da comunidade. Desse modo, o decreto possibilita que as autoridades ambientais exijam diagnósticos de impactos socioambientais e que sejam realizadas capacitações das comunidades para a gestão intrínseca das ações de turismo. 
A FUNAI (BRASIL, 2015), na Instrução Normativa oㅡ 03/2015 estabelece normas para a visitação com fins turísticos em Tls, de base comunitária e sustentável, nos segmentos de etnoturismo e de ecoturismo. O documento se configura em avanço quanto ao papel das empresas de turismo, uma vez que determina a apresentação à FUNAI, de um de plano de visitação e monitoramento. Exige ainda o registro para as autoridades de qualquer ocorrência de incidentes ou procedimentos ilícitos, com ênfase a possíveis impactos ambientais das atividades turísticas.

As populações tradicionais têm categorias próprias de nomear e classificar o ambiente e, por conviverem com a biodiversidade, não enxergam como um recurso natural, apenas com valor de uso, mas como seres vivos que têm também valor simbólico (SILVA et al., 2016).

Em estudo sobre a relação entre turismo e desenvolvimento local desenvolvida na reserva do Tupé, no Estado do Amazonas, foi verificado que o turismo preservacionista pode ser uma fonte de retroalimentação da preservação da natureza e dos costumes indígenas. Conforme um representante indígena da citada reserva, "[o turismo] faz com que os povos indígenas entendam melhor a preservar a natureza" (FURTUNATO; SILVA, 2011, p.15).

Todavia, em estudo de caso sobre as unidades de paisagem na $\mathrm{TI}$ em Itapipoca-CE, o potencial turístico é apontado com risco de exploração predatória e é feito o alerta para a necessidade de demarcação das terras, a fim de orientar adequadamente as formas de uso, ocupação de solo e desenvolvimento de atividades não agrícolas, fornecendo suporte para a preservação física e cultural daquele grupo étnico (MEIRELES, 2011).

As informações apresentadas sobre duas comunidades que se autorreconhecem indígenas, Mendonça do Amarelão e Caboclos do Assu, localizadas respectivamente nos municípios potiguares de João Câmara e Assu (Figura 1), foram obtidas através de observações in loco, registro fotográfico, diálogo informal com pessoas das comunidades e entrevistas com lideranças sobre aspectos sociais, econômicos, culturais e potencialidades turísticas.
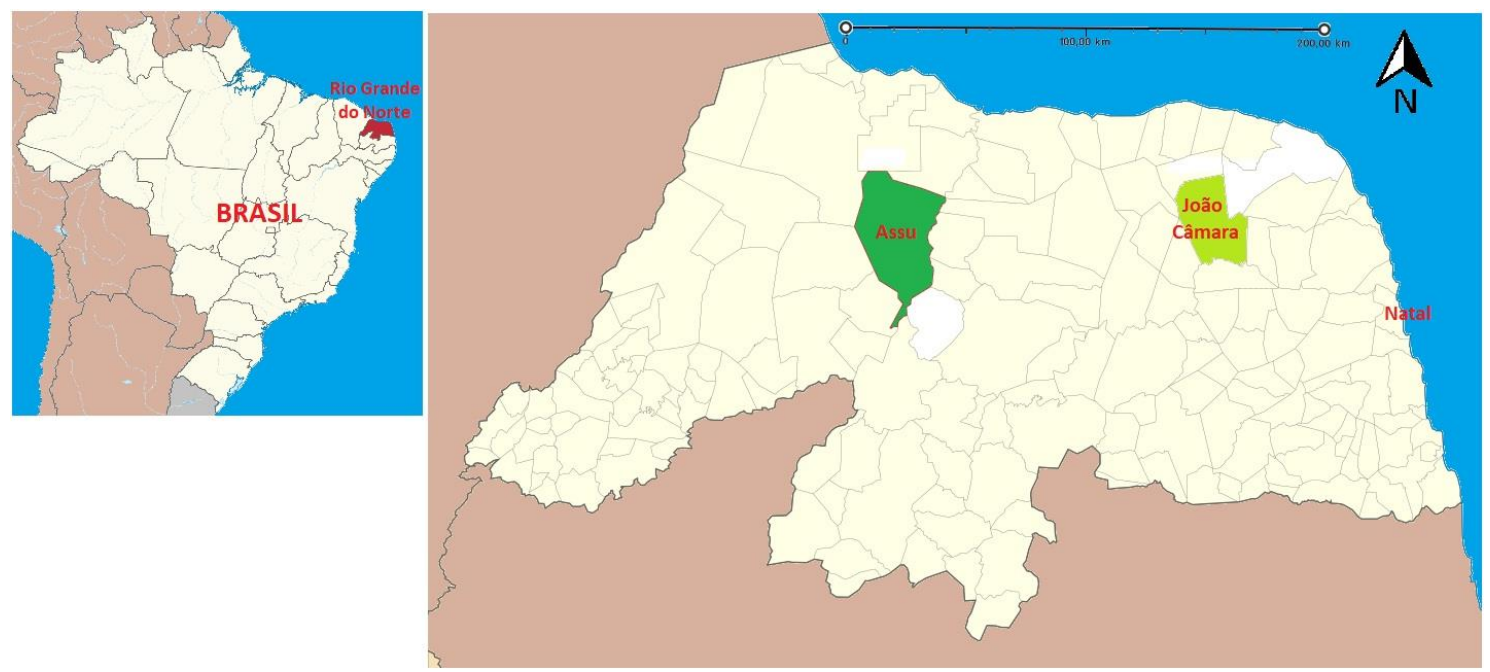

Figura 1: Municípios potiguares onde estão localizadas as comunidades Caboclos do Assu e Mendonça do Amarelão. Fonte: adaptado de IBGE (2017) e Open Brasil (2017) Figure 1: Cities from Rio Grande do Norte where the communities Caboclos do Assu and Mendonça do Amarelão are located. Source: Adapted from IBGE (2017) and Open Brasil (2017) 


\section{Comunidade Mendonças do Amarelão}

A Comunidade Amarelão localizada na região do Mato Grande na zona rural de João Câmara-RN, fica a $14 \mathrm{~km}$ da sede, sendo $10 \mathrm{~km}$ na BR 406 e $4 \mathrm{~km}$ de estrada de terra, com população estimada em 1.100 pessoas distribuídas em cerca de 300 famílias. A vegetação predominante é de caatinga, jurema, marmeleiro, cactos e bromélias entre outras; e os animais mais presentes são camaleões, tatu, peba, preá, raposa, veado, além de vários tipos de aves (SILVA, 2017; GUERRA, 2017).

De etnia potiguara e origem ligada aos índios "Tapuia" falantes do Tupi, o povo "Mendonça do Amarelão" recebe essa denominação devido ao ritual de culto ao sol, celebrado por seus antepassados (SILVA, 2017).

A principal fonte de renda na comunidade é o beneficiamento da castanha de caju, comercializada em João Câmara, Natal, região e em outros estados. O processo é realizado artesanalmente nos quintais das residências.

Os Mendonças passaram a autossustentação por meio do beneficiamento da castanha, como forma de permanecerem em seu território. Essa atividade familiar é regida pelo forte sentimento de pertença do grupo e de sua relação permanente com a terra. Assim, vale reforçar, o beneficiamento da castanha além de alternativa de sobrevivência é uma forma de garantia da permanência da família no seu lugar de origem. Esta atividade produtiva tem a participação ativa das mulheres em todas as etapas. Os locais de beneficiamento são barracas construídas nos quintais das casas, principalmente pelo fato de possibilitar às mulheres conciliar o trabalho com as atividades domésticas e cuidados com os filhos.

Além do beneficiamento da castanha, desenvolvem na cozinha comunitária da Associação Comunitária do Amarelão - ACA, produtos derivados da castanha como bolos, cocadas e farinha de castanha, onde também são confeccionados artesanatos. A comercialização da castanha é feita principalmente fora da comunidade, em outras cidades potiguares e em outros estados, assim como os demais produtos da comunidade como o artesanato, as comidas etc. Na agricultura são cultivados milho, feijão, batata doce, jerimum, melancia, umbu, entre outros produtos da agricultura familiar. Na pecuária alguns criam animais de pequeno porte para consumo próprio e comercialização do leite de vaca e esterco (SILVA, 2017).

Em relação à gastronomia, é típica de espécies vegetais regionais, a exemplo de feijão branco, batata doce, mandioca e seus derivados como a farinha, a tapioca e o beiju, além de produtos feitos à base de castanha como bolo, cocada e farinha $e$ a própria amêndoa (SILVA, 2017).

Somente um pequeno número de pessoas trabalha fora da comunidade. Sendo em grande parte homens com baixo grau de instrução formal que trabalham predominantemente na construção civil. Todavia, a maioria dos indígenas com formação acadêmica mora e atua na própria comunidade.

A infraestrutura local do Amarelão é composta por uma escola municipal de ensino fundamental, a sede da associação comunitária, quadra de esportes, posto de atendimento médico, quadra de futebol e duas igrejas, uma católica e outra evangélica (GUERRA, 2017).

Vale destacar que há uma escola de ensino médio em construção, com previsão de funcionamento para 2019, cujo projeto original foi idealizado pela Irmã 
Terezinha Galles, católica que atuou na comunidade, e pelas professoras do Amarelão Maria Ivoneide Santos Silva e Francisca Batista (Dona Chiquinha). O referido projeto foi entregue à Secretaria de Educação do Estado do RN em 2005. Em março de 2018 iniciou a concretização da construção da escola, resultado das reivindicações da comunidade e da parceria entre o governo do Estado e Banco Mundial. A escola atenderá todo o território indígena Mendonça, que abrange as comunidades Amarelão, Serrote de São bento, Açucena, Assentamento Santa Terezinha e Assentamento Marajó.

\section{Atrativos naturais e socioculturais da Comunidade Mendonças do Amarelão}

É relevante para o desenvolvimento de atividades etnoturísticas a preservação dos costumes indígenas. $\mathrm{Na}$ comunidade Amarelão, dentre os atrativos naturais e culturais preservados. Dentre os locais antigos, têm destaque uma casa de taipa, construída há mais de 70 anos e a cacimba salgada, local que marca a divisão social de territórios nas comunidades. Além de outros atrativos naturais e culturais, que inclui uma trilha ecológica de $4 \mathrm{~km}$, muito apropriada para visitantes com enfoque ecológico.

Por se tratar de uma comunidade que autoidentificada indígena, são fundamentais os "pontos de memória", com destaque para a pedra das letras (Figura 2), com registro de escritas rupestres dos primeiros povos que habitaram a região.

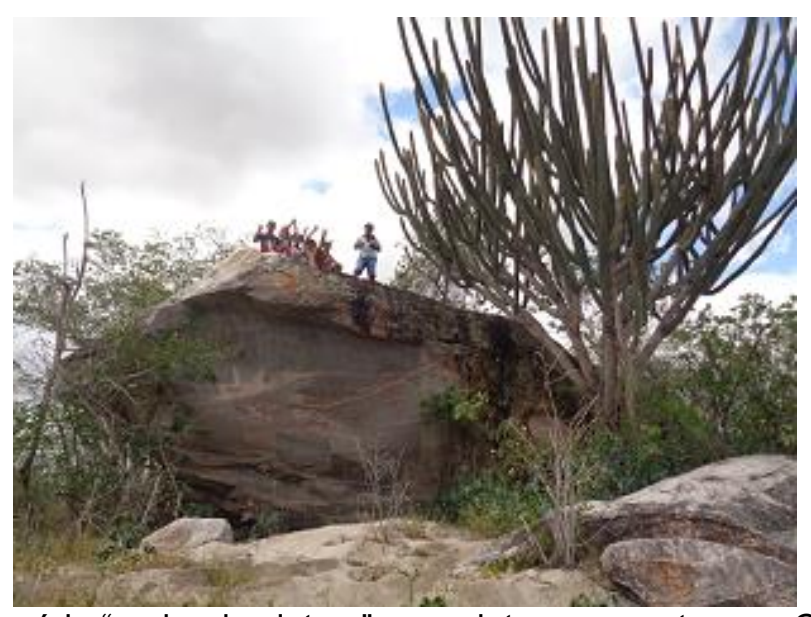

Figura 2: Ponto de memória "pedra das letras" com pinturas rupestres na Comunidade Amarelão. Figure 2: Historical Site "Pedra das Letras" (stone of the letters) with cave paintings in the Amarelão Community.

Um local de grande significado para a população é a gameleira (Figura 3), uma árvore com aproximadamente 300 anos, onde era realizada a feira para troca e compra de produtos da pesca, caça e agricultura - a referida feira passou por revitalização. 


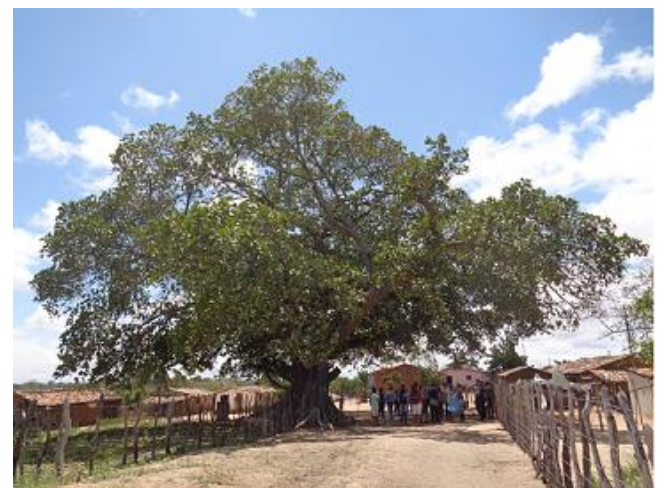

Figura 3: Ponto de memória "gameleira" com cerca de 300 anos na Comunidade Amarelão. Figure 3: Historical Site "Gameleira" that is about 300 years old in the Amarelão Community.

Outro ponto de memória que chama atenção por sua beleza cênica é uma rocha chamada pelos nativos de "pedra do sino", que ao bater na mesma com uma pedra ecoa um som semelhante ao de sino.

Os tanques de pedra (Figura 4), localizam-se em um lajedo com fendas formadas naturalmente, onde em seu entorno corre um riacho no período das chuvas, que é utilizado como espaço de lazer para banho.

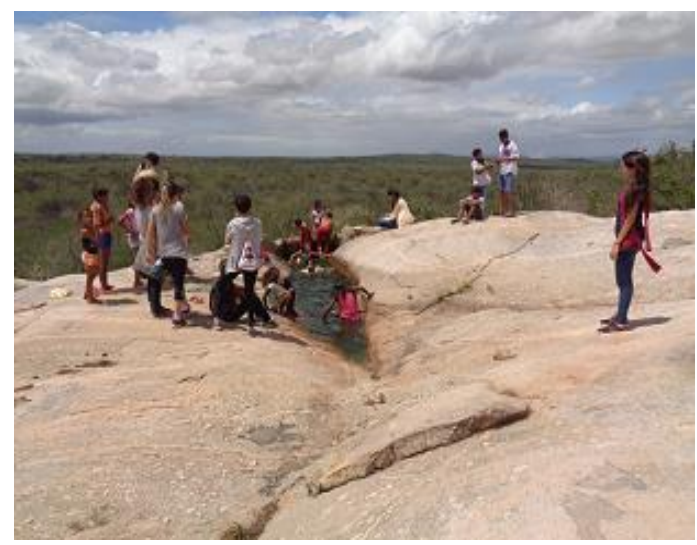

Figura 4: Ponto de memória "tanque de pedra" na Comunidade Amarelão.

Figure 4: Historical Site "Tanque de Pedra" (stone tank) in the Amarelão Community.

Um aspecto marcante da cultura desta etnia é o Toré, dança indígena potiguara (Figura 5), onde glorificam a mãe natureza e expressam seus sentimentos aos antepassados, além do resgate da língua Tupi de seus ancestrais.

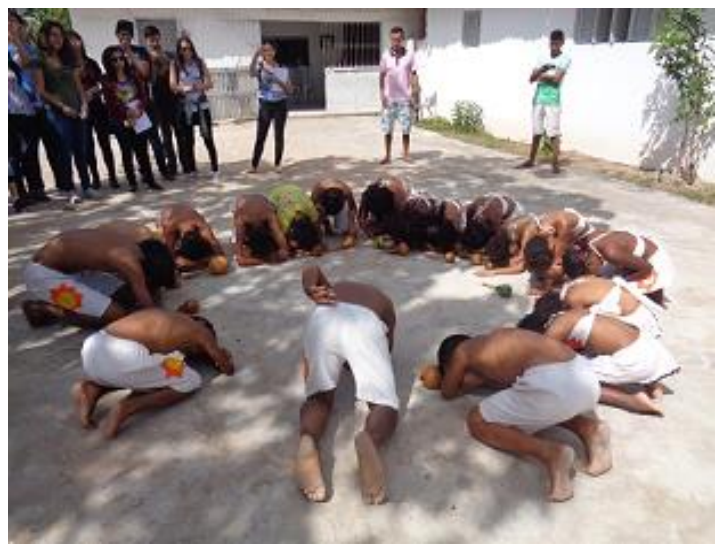

Figura 5: Ritual do Toré na Comunidade Amarelão.

Figure 5: Toré Ritual in the Amarelão Community. 
$\mathrm{Na}$ atual escola local de ensino fundamental é ensinada a língua Tupi e a dança do Toré, visando preservar a cultura indígena. Segundo informa uma liderança, a comunidade-inseriu o ensino tupi no currículo da escola local de $1^{\circ}$ ao $5^{\circ}$ ano, de modo que "as crianças já cantam os cantos do toré em tupi" (SILVA, 2017).

Como na maioria dos grupos indígenas localizados no Nordeste, o toré é uma importante prática ritual, capaz de balizar as diferenças internas, projetando os grupos nas situações de contato. No caso dos Potiguara, o toré é geralmente realizado nas comemorações do Dia do Índio (19 de abril), sendo pensado como um "ritual sagrado" que celebra a amizade entre as distintas aldeias, realçando 0 sentimento de grupo e de nação. É uma dança que está na própria percepção e representação da tradição coletiva, sendo, portanto, um elemento essencial para eles se pensarem enquanto possuidores de um passado histórico comum (ISA, 2017, p.1).

Outro atrativo cultural e relevante ponto de memória é a Linha Férrea, considera marco divisor das comunidades indígenas Amarelão e Assentamento Santa Terezinha. Onde, antigamente, era o único acesso à sede do município da cidade Baixa Verde, hoje João Câmara, atual capital da região do mato grande. As famílias Mendonça saíam das comunidades para o município a pé toda semana para fazer compras ou iam buscar carro para socorrer alguém doente ou mulher grávida, cujo parto fosse inviável pelas parteiras da comunidade.

A Festa da Castanha é uma atividade cultural promovida anualmente pela ACA e comunidade do Amarelão, com o apoio de parceiros. Essa festa começou a ser realizada na década de 1990 pelo primeiro presidente da ACA, sendo uma atividade de lazer e diversão para a comunidade. Em 2012, a coordenação da Associação e a comunidade retomaram a tradição, que se dá anualmente no último sábado de agosto, atraindo visitantes regionais, de outros estados e até estrangeiros de passagem no RN.

Os principais objetivos do evento são valorizar o trabalho desenvolvido na comunidade pelo fortalecimento da cadeia produtiva da castanha, promover o escoamento dos produtos locais e, dar assim, maior visibilidade e fortalecimento à identidade etnocultural dos Mendonças do Amarelão. O evento é bem diversificado e atrativo com exposição e comercialização de tudo o que é produzido a partir da castanha, além dos artesanatos locais. Tem ainda exposição de fotos e palestras sobre o povo indígena Mendonça do Amarelão e o processo de beneficiamento da castanha de caju; trilhas para visitação aos pontos de memória com escritas rupestres e o tanque de pedra; apresentações culturais como o Toré, a Banda de Flauta e a Orquestra Irmã Terezinha Galles formada por crianças e jovens indígenas. É realizado ainda um almoço comunitário, além de jogos, brincadeiras, apresentações artísticas teatrais e de grupos musicais.

Sobre os produtos comercializados vale enfatizar que têm a própria amêndoa, nas opções torrada natural, com sal e caramelizada; as comidas típicas feitas com a castanha como arroz, farofa, cocada, bolo, pavê e brigadeiro; e no artesanato indígena tem cocar, maracá, móbile, filtro dos sonhos, colares, pulseiras, anéis de coco, brincos, tererê e tiara, entre outros. 
Em relação à capacidade para recepcionar grupos, segundo a liderança, a comunidade tem experiência em receber professores, estudantes e intercâmbios entre comunidades, grupo de jovens etc. "Já servimos até 300 almoços e três refeições ao dia para 150 pessoas, numa conferência realizada na comunidade por três dias". Porém, destaca: "não temos experiência com turistas" (SILVA, 2017).

Diante do exposto, o turismo de base comunitária apresenta expressivo potencial na para o povo Mendonça do Amarelão. Além de contribuir para o resgate da memória e preservação cultural, propicia trabalho e renda. Quando realizado de forma sustentável, é uma forma de resistência, com viés educativo e disseminador ao propiciar a troca de conhecimentos e a desconstrução de esteriótipos.

\section{Comunidade Caboclos do Assu}

A comunidade Indígena Caboclos do Assu, está localizada na região Oeste potiguar, às margens da $\mathrm{RN} 233$, a aproximadamente $15 \mathrm{~km}$ da sede do município de Assu-RN e tem população estimada de 100 pessoas e cerca de 40 famílias. Os animais típicos da caatinga são verificados na comunidade, porém, devido à existência de diversas agroindústrias nas proximidades, ao desmatamento e outras atividades antrópicas tem reduzido de forma significativa a fauna local (LOPES, 2017).

Dentre as principais fontes de geração de renda, os homens em idade produtiva frequentemente trabalham em empresas regionais de fruticultura. Atualmente, a produção artesanal se limita a vassouras e bolsa de palha, feitos por uma moradora, mas já foram desenvolvidos outros itens (LOPES, 2017).

Em relação aos programas sociais governamentais de distribuição de renda, alguns recebem bolsa família, mas segundo relatos a renda não agrícola mais expressiva é a aposentadoria: "nunca recebi isso, mas tem muitos que têm e eu agradeço muito por todos, eu só tenho meu aposento"; "as pessoas trabalham nessa firma de banana, outros vai trabalhar fora, só os homens"; "aqui, quem não é aposentado, vai trabalhar fora do Assu, pra Ipanguaçu".

A dependência do trabalho externo nas empresas agrícolas de médio e grande porte, se deve historicamente aos latifúndios formados pela disputa por terras. Os Caboclos do Assu estão há pelo menos seis gerações dependendo da oferta de trabalho das agroindústrias e fazendas (OLIVEIRA, 2014). Nas terras que restaram, desenvolvem agricultura de sequeiro, com fins de subsistência e a produção de animais como bovinos, ovelhas, cabras e galinhas, também para consumo familiar (LOPES, 2017).

A comprovação da expulsão dos indígenas de suas terras, por parte daqueles que se diziam donos, é evidente em relatos de moradores: "as terras eram apropriadas 'no grito' e se convencia os moradores locais a se tornarem empregados", persuadidos pelo poder econômico dos fazendeiros. "Aqui somos meeiros e precisamos de autorização do fazendeiro até para pescar no açude".

As dificuldades locais ficam explícitas no depoimento de uma moradora: "aqui sofreram e sofreram muito, passar quatro ou cinco anos de seca, deixar a família morta de precisão dentro de casa, muitos dias forrar o chão com uma esteirinha velha pra se deitar mãe e filho, porque não tinha um cobertor pra se cobrir". 
Em termos de infraestrutura, a comunidade não dispõe de escola local. Por isso, as crianças são deslocadas em carro disponibilizado pela Prefeitura de Assu para escolas em Assu-RN, Paraú-RN e na comunidade vizinha Riacho, onde estudam o português e não há ensino de língua indígena. Grande parte das residências é de taipa. A Associação Comunitária de Caboclos do Assu ainda não tem sede própria e a Comunidade é assistida quinzenalmente pela Equipe Multidisciplinar de Saúde Indígena da SESAI - Secretaria Especial de Saúde Indigna do Ministério da Saúde. Por falta de local próprio, o atendimento médico e os encontros da associação são realizados na residência do Cacique Adriano (LOPES, 2017).

De etnia potiguara, os indígenas da comunidade Caboclos do Assu estão em um nível mais incipiente de desenvolvimento quando comparada ao Amarelão. Ainda assim, há a possibilidade de realizar ações voltadas para o turismo de base comunitária como forma de valorização e resgate histórico-cultural e geração de renda.

\section{Atrativos naturais e socioculturais da Comunidade Caboclos do Assu}

Em relação aos principais atrativos naturais e socioculturais presentes na comunidade indígena Caboclos do Assu, um destaque é o "Açude do Riacho" (Figura 6), utilizado para pesca e sedentização animal, principalmente das ovelhas. O local também é espaço de lazer para moradores e visitantes.

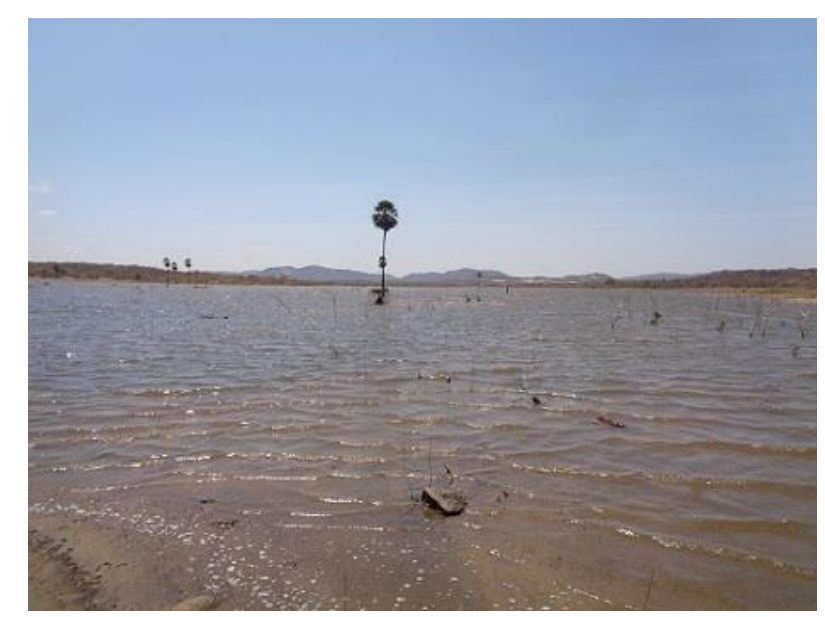

Figura 6: "Açude do Riacho" na Comunidade Caboclos do Assu Figure 6: "Weir" in the Caboclos do Assu Community

A vegetação nativa (Figura 7) expressa a diversidade da caatinga, com a presença especialmente de pereiro, jurema, mufumbo, juazeiro, cactus, mandacaru e bromélias.

Dentre os artefatos antigos, alguns moradores dispõem de ferro de passar roupa a carvão, pilão para pilar arroz e esteira de palha. 


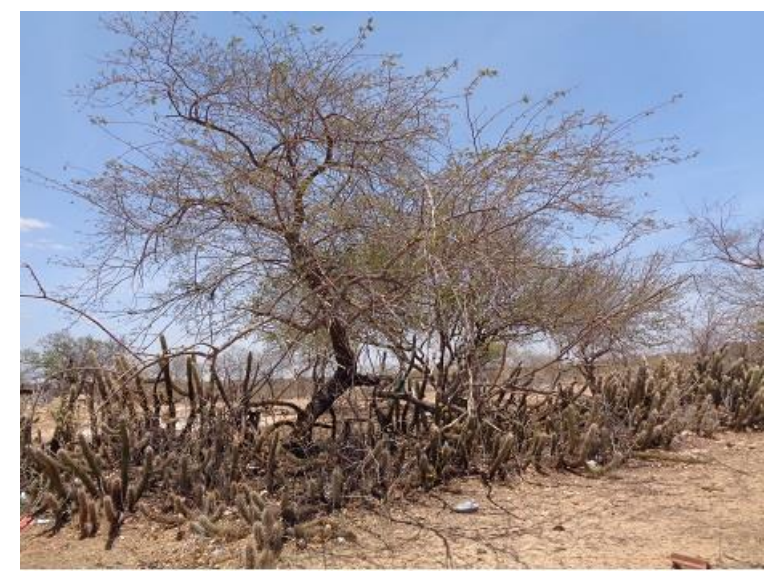

Figura 7: Vegetação nativa do bioma caatinga na Comunidade Caboclos do Assu

Figure 7: Native vegetation of the Caatinga biome in the Caboclos do Assu Community

É importante salientar que a maior riqueza do local encontra-se nas vidas das pessoas. A exemplo dos experientes irmãos "Zamba", Sr. Antonio Luis Lopes com 76 anos; e "Bolero", Sr. Antonio Francisco da Silva com 70 anos. Pessoas experientes e bastante conhecedoras da trajetória da etnia na região.

Diante das possibilidades apresentadas, é necessário destacar o limiar entre o turismo predatório e o turismo responsável, cuja gestão não sofra intervenção meramente exploratória de agências de turismo, mas que seja de base comunitária, onde exista responsabilidade social e preocupação com a preservação ambiental e costumes étnicos (PEREIRO, 2013).

\section{Considerações Finais}

As comunidades autoidentificadas indígenas, Mendonça do Amarelão (João Câmara-RN) e Caboclos do Assu (Assu-RN), têm potencialidades de geração de renda não agrícola. Dentre elas, o etnoturismo se configura como uma possibilidade. Embora a literatura destaque as limitações desse tipo de intervenção, é fundamental assegurar a sustentabilidade socioambiental e econômica, por meio da gestão de base comunitária.

A comunidade Mendonça do Amarelão apresenta condições relativamente favoráveis para o desenvolvimento do etnoturismo, por seus atrativos naturais com os "pontos de memória", o artesanato, a culinária e pela riqueza cultural do povo. $\mathrm{Na}$ comunidade Caboclos do Assu, o processo ainda se encontra bastante incipiente e a possibilidade etnoturística requer maior apoio de organizações governamentais e não governamentais.

Embora tenham diferentes contextos de infraestrutura, as lideranças demonstram interesse em desenvolver atividades voltadas para o turismo local, como uma das possibilidades de resgate e afirmação cultural e de geração de renda.

As populações de ambas comunidades indígenas já sofreram bastante impacto no processo histórico de aculturação e perda territorial e, nesse momento de autoidentificação, resgate cultural e luta territorial é preciso ter domínio sobre os rumos que se quer tomar, inclusive em projetos de cunho econômico. Por isso a preocupação de que a intervenção exógena interfira no tipo de turismo desenvolvido e a necessidade de implementação de políticas públicas que viabilizem projetos sustentáveis. 


\section{Referências}

ASSOCIAÇÃO COMUNITÁRIA DO AMARELÃO - ACA. Censo Comunitário do Amarelão 2018. João Câmara/RN, 2018, 41p.

ASSOCIAÇÃO NACIONAL DE AÇÃO INDIGENISTA - ANAÍ. Acompanhamento da situação fundiária das terras indígenas do Rio Grande do Norte. Disponível: $<$ http://www.anai.org.br/povos rn.asp > . Acesso: 17.04.2019.

BOFF. L. Sustentabilidade: o que é - o que não é. Petrópolis/RJ: Vozes, 2012.

BRASIL. FUNDAÇÃO NACIONAL DO ÍNDIO - FUNAI. Instrução Normativa no 03/2015, de 11 de junho de 2015, Estabelece normas e diretrizes relativas às atividades de visitação para fins turísticos em terras indígenas. 2015. Disponível em $<$ http://pesquisa.in.gov.br/ imprensa/isp/visualiza/index.jsp?jornal=1\&pagina= $\underline{41 \& \text { data }=12 / 06 / 2015}>$. Acesso em 19.04.2019.

BRASIL. FUNDAÇÃO NACIONAL DO ÍNDIO - FUNAI.FUNDAÇÃO NACIONAL DO ÍNDIO - FUNAI. <http://www.funai.gov.br/index.php/ indios-no-brasil/terrasindigenas> acesso: 19.03 .2019

BRASIL. FUNDAÇÃO NACIONAL DO ÍNDIO - FUNAI.Mapas. 2018. Disponível: $<$ http://www.funai.gov.br/index.php/servicos/ geoprocessamento>

Acesso: 16.04.2019.

BRASIL. INSTITUTO BRASILEIRO DE GEOGRAFIA E ESTATÍSTICA - IBGE. Os indígenas no Censo Demográfico 2010: primeiras considerações com base no quesito cor ou raça. 2012, 31p. Disponível em $<$ https://indigenas.ibge.gov.br/images/indigenas/estudos/ indigena censo 2010.pdf > Acesso em 07.03.2019.

BRASIL. INSTITUTO BRASILEIRO DE GEOGRAFIA E ESTATÍSTICA - IBGE. Mapas IBGE: Rio Grande do Norte. 2017. Disponível em $<$ https://mapas.ibge.gov.br> Acesso: 04.04.2019.

BRASIL. SUBCHEFIA DE ASSUNTOS JURÍDICOS DA CASA CIVIL. Decreto no 7.747/2012, de 05 de junho de 2012, Institui a Política Nacional de Gestão Territorial e Ambiental de Terras Indígenas - PNGATI, e dá outras providências. 2012. Disponível em <http://www.planalto.gov.br/ccivil 03/ Ato2011-2014/2012/Decreto/ D7747.htm>. Acesso em 19.04.2019.

CARVALHO, J.J. de. 'Espetacularização' e 'canibalização' das culturas populares na América Latina. Revista Anthropológicas. v.21, n.1, 2010.

CONSELHO INDIGENISTA MISSIONÁRIO - CIMI. Relatório violência contra os povos indígenas no Brasil - dados de 2016. 2016, 152p. Disponível em $<$ https://www.cimi.org. $\mathrm{br} /$ pub/relatorio/Relatorio-violencia-contra-povosindigenas 2016-Cimi.pdf> Acesso: 25.04.2019

FORTUNATO, R.A.; SILVA, L.S. Os significados do turismo comunitário indígena sob a perspectiva do desenvolvimento local: o caso da reserva de desenvolvimento sustentável do Tupé-AM. CULTUR - Revista de Cultura e Turismo. v.5, n.2, 2011. p. $85-100$.

GOMES, M.P. O caminho brasileiro para a cidadania indígena. In: PINSKY, Jaime; PINSKY, Carla Bassanezi. História da cidadania. 5.ed. São Paulo: Contexto, 2010. 
GUERRA, J. G. A. Mendonça do Amarelão: origem, migrações, aspectos de sua cultura e identidade étnica. Coleção Matiapoa - v. 1. João Pessoa/PB: Ideia, 2017.

INSTITUTO SOCIOAMBIENTAL - ISA. Potiguara. 2017. Disponível em <https://pib. socioambiental.org/pt/povo/potiguara/941>. Acesso em 07.03.2019.

LOPES, A.A. Entrevista concedida a MARTINS, J.C.V. Assu-RN. 05.10.2018.

MACEDO, H.A.M. Populações indígenas no sertão do Rio Grande do Norte: história e mestiçagens. Natal-RN: EDUFRN, 2011.

MEIRELES, A.J.A. Unidades de paisagem na Terra indígena Tremembé de São José e Buriti, Município de Itapipoca-CE. In: SILVA, E.V.; MEIRELES, A.J.A.; GORAYEB, A. (org.) Educação ambiental e indígena: caminhos da extensão universitária na gestão de comunidades tradicionais. Fortaleza: Edições UFC, 2011.

MELO, B.S. Índios do Rio Açu. Disponível em <https://www.recantodas letras.com.br/ cordel/4299854> Bencará [literatura de cordel] Acesso: 04.04.2018.

OPENBRASIL. Rio Grande do Norte. Disponível em $<$ http://riograndedonorte.openbrasil. org/>. Acesso: 04.11.2019.

OLIVEIRA, J. N. V. Revista de Humanidades: "ser índio" e "ser caboclo" potiguar: história indígena e o processo identitário nas comunidades dos caboclos do Assú. v.15, n.35, p.191-197, 2014.

OLIVEIRA, J. P. Uma etnologia dos "índios misturados"? Situação colonial, territorialização e fluxos culturais. Mana, Rio de Janeiro, v. 4, n. 1, p. 47-77, Apr. 1998.

PEREIRO, X. Los efectos del turismo en las culturas indígenas de América Latina. Revista Española de Antropología Americana. 2013, v. 43, n. 01, p. 155-174.

Relatório Final da II ASSEMBLÉIA DOS POVOS INDÍGENAS DO RIO GRANDE DO NORTE - II AIRN, realizada na Casa de Cultura Popular Palácio Antônio Bento Goianinha-RN, de 22 a 23 de novembro de 2011 (impresso).

SILVA, M.E.C; LOPES, J.B.; BARROS, R.F.M.; ALENCAR, N..L.; MENDES, L.M.S. A etnoconservação no contexto da agrobiodiversidade: diálogos entre os saberes científicos e locais em tempos de crise ambiental. Espacios. v. 37, n. 37, 2016.

SILVA, M. I. S. Entrevista concedida a MARTINS, J.C.V. João Câmara-RN, 02.10.2018.

SOUZA, E.P.; MARTINS, S.R.O.; ARAÚJO, A.P.C. Fronteira etnocultural e desenvolvimento rural: o produto turístico "trem do pantanal" no distrito de Taunay. ACTA Geográfica, v.5, n.10, jul./dez. de 2011. pp.37-53.

VIEIRA, J. G.; KÓS, C. Invisibilidade, resistência e reconhecimento. In: RICARDO B.;

RICARDO F. Povos Indígenas do Brasil 2011/2016. São Paulo: Instituto Socioambiental 2017 (p.519-522). 


\title{
Agradecimentos
}

Às lideranças das comunidades, pelas valiosas informações.

À Universidade Federal Rural do Semi-árido - UFERSA e ao Conselho Nacional de Desenvolvimento Científico e Tecnológico - CNPq, pela concessão de bolsa por meio do Programa Institucional de Bolsas de Iniciação Científica (PIBIC/UFERSA/CNPq), via Edital IC no 10/2017-2018 e Edital IC no 05/2018-2019.

\section{Notas:}

${ }^{1}$ Matéria completa sobre a expedição, que aconteceu em 11/07/2017 o qual o jornalista dar ênfase nos potenciais turístico existentes na região dos Pilões, em especial no local visitado, a Serra do Bandeira residente dentro de várias propriedades rural na região. Disponível em: $<$ http://primeirapagina.to/noticias/pinturas-rupestres-em-miracema-um-tesouro-ainda-poucoexplorado/> Acesso em 27/jun/2019.

2 Informações sobre o dia da aprovação do projeto que aconteceu em 17 de outubro na câmara municipal de Miracema do Tocantins, com a presença dos representantes da Ruraltins na ocasião. Disponível em <https://ruraltins.to.gov.br/noticia/2018/10/17/projeto-delei-incentiva-associacao-agroturistica-na-regiao-de-miracema/> em 27/06/2019.

${ }^{3}$ A região dos Pilões integrou-se ao pontos turísticos do município em 2019, como consta em seu site oficial disponível em: <https://miracema.to.gov.br/cidade/pontos-turisticos>. Acesso em 27/.jun.2019.

Jacqueline Cunha de Vasconcelos Martins: Universidade Federal Rural do Semiarido, Mossoró, RN, Brasil.

E-mail: jacquelinevasconcelos@ufersa.edu.br

Link para o currículo Lattes http://lattes.cnpq.br/3819491155539636

\section{Tayse Michelle Campos da Silva}

Liderança da Comunidade Indígena do Amarelão

Universidade Federal do Rio Grande do Norte, Natal, RN, Brasil

E-mail: tayse.potiguararn@hotmail.com

Link para o currículo Lattes http://lattes.cnpq.br/9052914121181431

\author{
Alan Martins de Oliveira \\ Universidade Federal Rural do Semiárido, Mossoró, RN, Brasil \\ E-mail: alanmartins@ufersa.edu.br \\ Link para o currículo Lattes http://lattes.cnpq.br/2105147275400017
}

\section{Edson Vicente da Silva}

Universidade Federal do Ceará, Fortaleza, CE, Brasil

E-mail: cacau@ufc.br

Link para o currículo Lattes http://lattes.cnpq.br/3354228537186786

\section{Ingride Pamilly Ribeiro Araujo de Oliveira}

Universidade Federal Rural do Semiárido, Mossoró, RN, Brasil

E-mail: ingridepamilly@hotmail.com

Link para o currículo Lattes http://lattes.cnpq.br/7590014309114426

Data de submissão: 02 de maio de 2019

Data de recebimento de correções: 09 de maio de 2019

Data do aceite: 09 de maio de 2019

Avaliado anonimamente 